\title{
CLM4-BeTR, a generic biogeochemical transport and reaction module for CLM4: model development, evaluation, and application
}

\author{
J. Y. Tang, W. J. Riley, C. D. Koven, and Z. M. Subin \\ Department of Climate and Carbon Sciences, Earth Sciences Division, Lawrence Berkeley National Lab (LBL), \\ Berkeley, CA, USA
}

Correspondence to: J. Y. Tang (jinyuntang@lbl.gov)

Received: 7 August 2012 - Published in Geosci. Model Dev. Discuss.: 10 September 2012

Revised: 18 December 2012 - Accepted: 2 January 2013 - Published: 29 January 2013

\begin{abstract}
To improve regional and global biogeochemistry modeling and climate predictability, we have developed a generic reactive transport module for the land model CLM4 (called CLM4-BeTR (Biogeochemical Transport and Reactions)). CLM4-BeTR represents the transport, interactions, and biotic and abiotic transformations of an arbitrary number of tracers (aka chemical species) in an arbitrary number of phases (e.g., dissolved, gaseous, sorbed, aggregate). An operator splitting approach was employed and consistent boundary conditions were derived for each modeled subprocess. Aqueous tracer fluxes, associated with hydrological processes such as surface run-on and run-off, belowground drainage, and ice to liquid conversion were also computed consistently with the bulk water fluxes calculated by the soil physics module in CLM4. The transport code was evaluated and found in good agreement with several analytical test cases using a time step of $30 \mathrm{~min}$. The model was then applied at the Harvard Forest site with a representation of depth-dependent belowground biogeochemistry. The results indicated that, at this site, (1) CLM4-BeTR was able to simulate soil-surface $\mathrm{CO}_{2}$ effluxes and soil $\mathrm{CO}_{2}$ profiles accurately; (2) the transient surface $\mathrm{CO}_{2}$ effluxes calculated based on the tracer transport mechanism were in general not equal to the belowground $\mathrm{CO}_{2}$ production rates with the magnitude of the difference being a function of averaging timescale and site conditions: differences were large $(-20 \sim 20 \%)$ on hourly, smaller $(-5 \sim 5 \%)$ at daily timescales, and persisted to the monthly timescales with a smaller magnitude $(<4 \%)$; (3) losses of $\mathrm{CO}_{2}$ through processes other than surface gas efflux were less than $1 \%$ of the overall soil respiration; and (4) the contributions of root respiration and heterotrophic respiration have distinct temporal signals in
\end{abstract}

surface $\mathrm{CO}_{2}$ effluxes and soil $\mathrm{CO}_{2}$ concentrations. The development of CLM4-BeTR will allow detailed comparisons between ecosystem observations and predictions and insights to the modeling of terrestrial biogeochemistry.

\section{Introduction}

The trajectory of ongoing climate change (Intergovernmental Panel on Climate Change (IPCC), 2007) depends strongly on greenhouse gas (e.g., $\mathrm{H}_{2} \mathrm{O}, \mathrm{CO}_{2}, \mathrm{CH}_{4}$, and $\mathrm{N}_{2} \mathrm{O}$ ) exchanges between the terrestrial biosphere and atmosphere. Globally, gross terrestrial ecosystem greenhouse gas fluxes are at least an order of magnitude larger than anthropogenic emissions and have strong climate sensitivity, which can lead to positive feedbacks with the atmosphere (e.g., Cox et al., 2000, Torn and Harte, 2006). Thus, accurately modeling terrestrial biogeochemistry is a critical component of earth system models (Friedlingstein et al., 2006).

Much effort has been dedicated to designing terrestrial biogeochemistry models that account for hydrological, energy, and carbon and nitrogen dynamics (e.g., Randerson et al., 1997; Thornton et al., 2002, 2007; Zhuang et al., 2003 and many others). Many of these existing efforts have used, in each terrestrial gridcell, a single vertically integrated layer for soil biogeochemistry, which we refer to here as a "bucket formulation", as it is analogous to the single-layer hydrology used in early soil-vegetation-atmosphere transfer (SVAT) models. This formulation is insufficient to resolve the depth-dependent soil biogeochemistry, which depends on interactions between the atmosphere, plants, microbes and soils. A good example for the deficiency of the

Published by Copernicus Publications on behalf of the European Geosciences Union. 
bucket formulation is the treatment of wetland ebullition of trace gases, such as methane $\left(\mathrm{CH}_{4}\right)$. A sufficient amount of volatile gases (both biogenic and non-biogenic) should be accumulated before the gas column becomes unstable such that convection is triggered to move the gas rapidly from the deep soil up to the soil surface. The convection process can vary drastically under different atmospheric and soil physical conditions, with ebullition happening in some cases and not others, despite similar total soil gas pressures (e.g., Tokida et al., 2007). Another example is the characterization of the aerobic and anaerobic environments in soil, which can have large vertical gradients (and horizontal gradients as well) that the bucket models cannot represent, but clearly affect which processes are dominating the soil biogeochemistry (e.g., Tang et al., 2010; Riley et al., 2011; Grant and Roulet, 2002; Maggi et al., 2008). In addition, the existing bucket-type models cannot simulate biogeochemical variables that are directly comparable with measurements. For example, the $\mathrm{CO}_{2}$ from soil respiration is often assumed to be measurable at the soil surface instantly after the plant root and soil microorganisms produce it (i.e., the production equals surface efflux assumption), although the characteristic time for transport from the surface to $20 \mathrm{~cm}$ depth in a sandy loam soil at $60 \%$ water-filled pore space, for example, is $\sim 10-20 \mathrm{~h}$, depending on the model used to calculate gas-phase diffusivity (Riley, 2005). As such, the bucket-type models cannot resolve episodic greenhouse gas emissions such as those due to freeze-thaw cycles (e.g., Mastepanov et al., 2008). The assumption of production equals surface efflux could also lead to incorrect parameterizations when the soil surface gas efflux measurements are used to calibrate the biogeochemistry submodel.

Depending on the philosophy of the model developers and the model's intended applications, soil biogeochemistry can be represented with different conceptual structures and model complexities. A few attempts have been made to model the soil-plant-atmosphere exchange of trace gases using a reactive transport modeling (RTM) approach (e.g., Simunek and Suarez, 1993; Fang and Moncrieff, 1999; Grant, 1993; Walter and Heimann, 2000; Tang et al., 2010; Wania et al., 2010; Riley et al., 2011). However, the majority of carbon cycling models still have the one-layer bucket structure, such as the Terrestrial Ecosystem Model (e.g., Zhuang et al., 2003), CENTURY (e.g., Kelly et al., 1997), CASA (e.g., Potter et al., 2003), and CLM-CN (e.g., Thornton et al., 2007).

Existing soil biogeochemical models (either the bucket type formulation or the RTM based formulation) integrated with climate simulating systems usually do not have the ability to represent biogeochemical processes with different levels of complexity by restricting the model designation to a single conceptual structure, which creates a barrier to understand the effects of model structural uncertainty on the simulated carbon-nutrient cycles and their interactions with other components of the climate system. Such designation also makes it difficult to consistently incorporate future developments. For example, most existing methane models focus either only on $\mathrm{CH}_{4}$, or on both $\mathrm{CH}_{4}$ and oxygen $\left(\mathrm{O}_{2}\right)$, where the latter is used to determine when a given soil layer, or fraction of the soil layer, is sufficiently aerobic or anaerobic to support the activities of methanotrophs or methanogens. An exception is the model documented in Tang et al. (2010), where they solved a system with up to four chemical species $\left(\mathrm{CH}_{4}, \mathrm{CO}_{2}, \mathrm{~N}_{2}\right.$, and $\left.\mathrm{O}_{2}\right)$ in gaseous and aqueous phases and considered three different conceptual structures to enable a hierarchical modeling of methane dynamics at different levels of model complexities. This approach allowed them to explore how methane dynamics depended on the different processes being represented. Still, processes such as adsorption and desorption were not considered there, because no sorptive species such as $\mathrm{NH}_{4}^{+}$or dissolved organic carbon (DOC) were involved in their study, which are critical for a mechanistic modeling of the nitrogen cycle (e.g., Maggi et al., 2008; Gu et al., 2009).

Field studies also indicate that it is important to consider slower processes such as bio-turbation (e.g., Yoo et al., 2011) and cryoturbation (e.g., Kaiser et al., 2007) in order to correctly model biogeochemistry in some terrestrial ecosystems. These slow processes have been included in some terrestrial biogeochemistry models (Jenkinson and Coleman, 2008; Koven et al., 2009); however, to our knowledge, no current land model in climate simulating systems exists that integrates both slow and fast processes contributing to vertical differences in biogeochemical cycling.

As understanding of terrestrial ecosystem processes improve, we face the situation of revising biogeochemistry models to incorporate new processes while not losing the legacy of previous model development (see Schmidt et al., 2011 for a perspective discussion on such needs). This situation motivates the development of a generic model template that can relatively easily accommodate new model structures and processes. To meet this and other challenges discussed above, we present here the development of CLM4-BeTR, which includes a flexible modeling structure of terrestrial ecosystem biogeochemistry and a generic multi-phase reaction and transport capability. CLM4-BeTR is integrated in CLM4 (Oleson et al., 2010), which is the land component of the Earth System Model CESM1.0, thereby allowing simulations that integrate processes involving plants, soils, ocean, atmosphere, urban areas, and land and sea ice. We organize the paper as follows: Sect. 2 describes model structure and parameterization, numerical methods, and theoretical predictions; Sect. 3 presents site level model evaluations; and Sect. 4 presents an example application. Finally, we conclude with a summary in Sect. 5 . 


\section{Model description}

CLM4-BeTR is designed to use a hierarchy of subsurface biogeochemistry models with different levels of complexity and structures and to couple the biogeochemical processes tightly with the physical processes, such that model predictions are as relevant as possible to what can be measured in field experiments (Fig. 1). In designing this model structure, we consider the close coupling between various components of a soil-plant-atmosphere system and track the physical (e.g., advection and diffusion), biophysical (e.g., bioturbation), chemical (e.g., aqueous chemistry), biochemical (e.g., microbial degradation), and biological dynamics (e.g., microbial physiology) of an arbitrary number of tracers. Throughout this study, we name any chemical species of interest as a tracer in order to be consistent with the terminology that is adopted in atmospheric biogeochemistry, to which that CLM4-BeTR will be coupled in our future studies. Specifically, we, starting from the atmosphere, consider tracers precipitated to the soil surface and plant canopy through both dry and wet atmospheric deposition. Volatile tracers such as $\mathrm{CO}_{2}$ and water vapor are allowed to pass through stomata and enter leaves. Liquid and solid aqueous tracers are allowed to drip off leaves and onto the soil surface. As in the default CLM4, plant litter falls onto the ground and proceeds through a cascade of decomposition. With the microbially-regulated decomposition of litter-derived organic matter and of plant root exudates, relevant tracers are released into the soil and are allowed to move and interact with flowing water and other chemical tracers through both biogeophysical and biogeochemical pathways. All aqueous tracers are allowed to move out of the soil column when the water is drained away, through both over-surface and sub-surface runoff. Volatile tracers are allowed to evaporate back into the soil pore space and atmosphere, and diffuse between the two. Such a structure also makes it possible to extend the depth-resolved modeling approach from the soil into the canopy air and connect with atmospheric chemistry and physics modules.

Below, we first derive the lumped equations for the reactive transport system. Based on the physical characteristics of the different processes, the operator splitting approach (e.g., Strang, 1968) is applied to solve the governing equations. Consistent boundary conditions are presented for the advective and diffusive transport of tracers. Numerical implementations are also presented for solving the advection and diffusion equations, followed by descriptions of the methods that are used to diagnose tracer fluxes associated with belowground water flow.

\subsection{The governing equation}

We formulate the general multiphase (here for three phases: solid, aqueous, and gaseous) advection-diffusion-reaction equation as

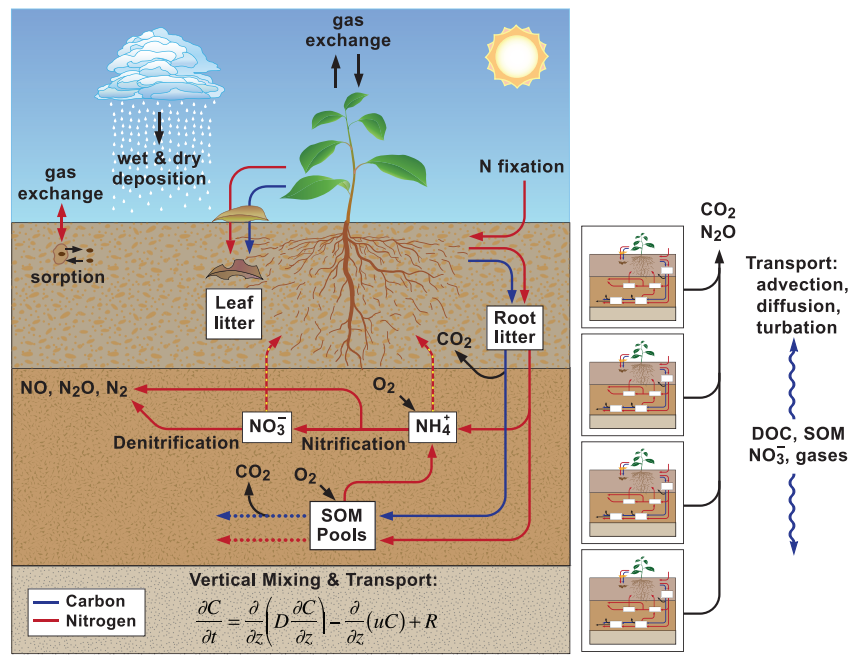

Fig. 1. Model structure of CLM4-BeTR: the example is based on the carbon and nitrogen cycles.

$$
\begin{aligned}
& \frac{\partial}{\partial t}\left(C_{\mathrm{s}}+\theta C_{\mathrm{W}}+\varepsilon C_{\mathrm{g}}\right)= \\
& \quad \frac{\partial}{\partial z}\left(D_{\mathrm{s}} \frac{\partial C_{\mathrm{s}}}{\partial z}\right)+\frac{\partial}{\partial z}\left(\theta D_{\mathrm{w}} \frac{\partial C_{\mathrm{w}}}{\partial z}\right)+\frac{\partial}{\partial z}\left(\varepsilon D_{\mathrm{g}} \frac{\partial C_{\mathrm{g}}}{\partial z}\right), \\
& \quad-\frac{\partial\left(u_{\mathrm{w}} C_{\mathrm{w}}\right)}{\partial z}-\frac{\partial\left(u_{\mathrm{g}} C_{\mathrm{g}}\right)}{\partial z}+R
\end{aligned}
$$

where $C_{x}, x=\mathrm{s}, \mathrm{w}, \mathrm{g}\left(\right.$ mol tracer $\left.\mathrm{m}^{-3}\right)$ are tracer concentrations in solid, aqueous, and gaseous phases, respectively; $D_{x}, x=\mathrm{s}, \mathrm{w}, \mathrm{g}\left(\mathrm{m}^{2} \mathrm{~s}^{-1}\right)$ are diffusivities for tracers in solid (e.g., Koven et al., 2009), aqueous, and gaseous phases, respectively; $u_{x}, x=\mathrm{w}, \mathrm{g}\left(\mathrm{m} \mathrm{s}^{-1}\right)$ are the advective velocities for aqueous and gaseous tracers, respectively, which are provided by the soil physics model; $\theta\left(\mathrm{m}^{3} \mathrm{~m}^{-3}\right)$ is the water filled soil porosity; $\varepsilon\left(\mathrm{m}^{3} \mathrm{~m}^{-3}\right)$ is the air filled porosity; $z(\mathrm{~m})$ is the spatial coordinate (positive downward); $t$ (s) represents time; and $R$ (mol tracer $\mathrm{m}^{-3} \mathrm{~s}^{-1}$ ) defines the net tracer production rate at time $t$ and depth $z$. Other soil processes such as erosion (Nearing et al., 1994), aggregation and disaggregation (Heuvelink and Pebesma, 1999), sedimentation transport (Merritt et al., 2003), and bioclogging (e.g., Maggi and Porporato, 2007) could also be incorporated into Eq. (1), provided the soil physical processes are modeled consistently. The tracer movement due to horizontal water flow is treated as a separate process and described in Sect. 2.4.

In Eq. (1), we considered diffusive and advective transport for both the aqueous and gaseous tracers. The vertical movement of the adsorbed $(s)$ phase is parameterized as a diffusive process as in Koven et al. (2009). The reaction term $R$ includes both net chemical production inside the soil and fluxes due to plant roots, e.g., autotrophic respiration, exudation, and possible transpiration induced fluxes, e.g., $\mathrm{NO}_{3}^{-}$ uptake through roots (Plhak, 2003) and soil $\mathrm{CO}_{2}$ transport through root systems into xylem water (Teskey et al., 2008).

Equation (1) is sufficiently general that it can represent the transport of any well-defined chemical tracer. For example, 
by ignoring the transport of water vapor in soil, Eq. (1) is reduced to the soil water budget equation currently implemented in CLM4,

$\frac{\partial}{\partial t}\left(C_{\mathrm{s}}+\theta C_{\mathrm{w}}\right)=-\frac{\partial u_{\mathrm{w}} C_{\mathrm{w}}}{\partial z}-q_{\mathrm{T}}$,

where $C_{\mathrm{s}}$ and $C_{\mathrm{w}}$ effectively represent the molar concentrations of ice and liquid water, respectively and $q_{\mathrm{T}}$ (mol water $\mathrm{m}^{-3} \mathrm{~s}^{-1}$ ) represents the sink of water due to transpiration.

We adopted the fast equilibrium assumption, i.e., equilibrium of tracer concentrations between phases is instantaneously achieved (e.g., Maggi et al., 2008). For instance, $\mathrm{NH}_{3}$ is considered to exist in three phases in equilibrium: gaseous, lumped aqueous, and adsorbed solid. The lumped aqueous phase includes both $\mathrm{NH}_{4} \mathrm{OH}$ and free $\mathrm{NH}_{4}^{+}$, whose relative concentrations are determined by the equilibrium stoichiometry:

$\mathrm{NH}_{4} \mathrm{OH} \leftrightarrow \mathrm{NH}_{4}^{+}+\mathrm{OH}^{-}$.

Adopting Eq. (3) enables one to group $\mathrm{NH}_{4} \mathrm{OH}$ and $\mathrm{NH}_{4}^{+}$ into a single tracer $\left(\mathrm{NH}_{4}^{\mathrm{X}}\right)_{\mathrm{w}}$, which is related to $\mathrm{NH}_{4} \mathrm{OH}$ through

$\left[\left(\mathrm{NH}_{4}^{\mathrm{X}}\right)_{\mathrm{w}}\right]=k_{\mathrm{NH}_{3}, \mathrm{NH}_{4}^{+}}\left[\mathrm{NH}_{4} \mathrm{OH}\right]$,

where the equilibrium constant $k_{\mathrm{NH}_{3}, \mathrm{NH}_{4}^{+}}$(unitless) is a function of $\mathrm{pH}$ and temperature. Further, invoking Henry's law, one has $\left[\mathrm{NH}_{4} \mathrm{OH}\right]=B\left[\left(\mathrm{NH}_{3}\right)_{\mathrm{g}}\right]$, where $B$ (unitless) is the Bunsen solubility coefficient (Sander, 1999). Therefore, we have the bulk concentration of $\mathrm{NH}_{4}^{\mathrm{X}}$ :

$$
\left[\mathrm{NH}_{4}^{\mathrm{X}}\right]=\theta\left[\left(\mathrm{NH}_{4}^{\mathrm{X}}\right)_{\mathrm{w}}\right]+\varepsilon\left[\left(\mathrm{NH}_{3}\right)_{\mathrm{g}}\right]+\left[\left(\mathrm{NH}_{4}^{+}\right)_{\mathrm{s}}\right],
$$

as the single state variable to represent the chemical species related to $\mathrm{NH}_{3}$. In Eq. (4), $\left(\mathrm{NH}_{4}^{+}\right)_{\mathrm{s}}$ is the adsorbed phase, which is assumed to be in equilibrium with free $\mathrm{NH}_{4}^{+}$dissolved in water, with a sorption parameter dependent on $\mathrm{pH}$, soil texture, and soil organic matter content.

Similarly, the bulk concentration of $\mathrm{CO}_{2}^{\mathrm{X}}$ is defined as

$$
\begin{aligned}
& \mathrm{CO}_{2}^{\mathrm{X}}=\theta\left[\left(\mathrm{CO}_{2}^{\mathrm{X}}\right)_{\mathrm{w}}\right]+\varepsilon\left[\left(\mathrm{CO}_{2}\right)_{\mathrm{g}}\right] \\
& =\theta\left(\left[\mathrm{H}_{2} \mathrm{CO}_{3}\right]+\left[\mathrm{HCO}_{3}^{-}\right]+\left[\mathrm{CO}_{3}^{2-}\right]\right)+\varepsilon\left[\left(\mathrm{CO}_{2}\right)_{\mathrm{g}}\right],
\end{aligned}
$$

where the relative concentrations of $\mathrm{H}_{2} \mathrm{CO}_{3}, \mathrm{HCO}_{3}^{-}$, and $\mathrm{CO}_{3}^{2-}$ are determined by their equilibrium stoichiometry (e.g., Maggi et al., 2008; Gu et al., 2009).

\subsection{Numerical implementation}

We used the operator splitting approach (e.g., Strang, 1968) to solve Eq. (1), which allowed us to use standard numerical solvers to deal with different processes while maintaining numerical efficiency. We grouped the various processes into three different terms, allowing us to rewrite Eq. (1) as

$\frac{\partial C_{\mathrm{blk}}}{\partial t}=\mathrm{Dif}+\mathrm{Adv}+R$,

where $C_{\mathrm{blk}}\left(\mathrm{mol}\right.$ tracer $\left.\mathrm{m}^{-3}\right)$ is the bulk tracer concentration, including contributions from all possible phases; Dif, Adv, and $R$ represent, respectively, the impacts of diffusion, advection, and reaction ( $\mathrm{mol}$ tracer $\mathrm{m}^{-3} \mathrm{~s}^{-1}$ ).

Using the Strang splitting approach (Strang, 1968), we represented Eq. (7) as

$C_{\mathrm{blk}}(t+\Delta t)=$

$(\operatorname{Dif}, \Delta t / 2)(\operatorname{Adv}, \Delta t / 2)(R, \Delta t)(\operatorname{Adv}, \Delta t / 2)(\operatorname{Dif}, \Delta t / 2)$,

where $(x, \Delta t)$ denotes the integration of process $x$ over a time step $\Delta t$ (s). This operator splitting formulation also allows us to consider the horizontal transport of the tracers, making our development easily implemented in models that have 3-D tracer transport capability. The integrations in Eq. (8) are done consecutively from right to left, where the solution from a previous integration is used as an initial condition for the next. All these integrals are formulated using the finite volume method (e.g., Eymard et al., 1999).

The soil physical variables (such as temperature, liquid and ice content of soil water and snow, water table, vertical and horizontal water fluxes) to drive Eq. (8) are provided by the soil physics module of CLM4, which solves the mass and energy transport equations of water and soil (Oleson et al., 2010). Aqueous and gaseous tracer diffusivities are computed as a function of soil moisture and soil temperature (Appendix A). The solid phase tracer (including adsorbed phase) diffusion is considered as a much slower process (e.g., Koven et al., 2009), such that it can be separated from Eq. (8) and calculated after the movement of aqueous and gaseous tracers. Specifically, by writing the diffusion processes in Eq. (8) as $($ Dif, $\Delta t / 2)=\left(\operatorname{Dif}_{\mathrm{s}}, \Delta t / 2\right)\left(\operatorname{Dif}_{\mathrm{gw}}, \Delta t / 2\right)$, where Dif $f_{\mathrm{s}}$ represents diffusion of solid phase tracer, and Dif ${ }_{\mathrm{gw}}$ represents diffusion of aqueous and gaseous phase tracer, it can then be shown that $C_{\mathrm{blk}}(t+\Delta t)=\left(\mathrm{Dif}_{\mathrm{s}}, \Delta t / 2\right) C_{\mathrm{blk}}^{*}(t+\Delta t)\left(\mathrm{Dif}_{\mathrm{s}}, \Delta t / 2\right)$, where $C_{\mathrm{blk}}^{*}(t+\Delta t)$ represents the tracer update due to processes other than solid phase diffusion. Thus, because the temporal updating of the tracer concentration is done iteratively, the solid phase tracer diffusion becomes a process that can be split from the other processes.

\subsubsection{Diffusive transport}

The Crank-Nicolson approach (e.g., Press et al., 1986) was used to solve the diffusion process. In contrast to previous approaches, which only consider the existence of a single water table level (or, more generally, wetting front) and restrict it to the connecting interface between two consecutive grid layers, in this study we allow multiple water table levels 
to coexist inside the soil (to accommodate the existence of perched water table, Swenson et al., 2012), and they can be within the grid layer rather than being restricted to the grid interface. However, only one wetting front is allowed to exist in a single grid layer, though our approach is extendable to consider more general cases. Specifically, the incoming flux from layer $j-1$ to layer $j$ ( $j$ increases with depth) is computed as (Fig. 2)

$F_{j-1 \rightarrow j}=-r_{j-1}^{-1}\left(a C_{j}-C_{j-1}\right)$,

and the outgoing flux from layer $j$ to layer $j+1$ is computed as

$F_{j \rightarrow j+1}=-r_{j}^{-1}\left(C_{j+1}-b C_{j}\right)$,

where

$$
\begin{aligned}
r_{j-1} & =\frac{\Delta z_{j-1}}{2 D_{j-1}}+\frac{\Delta z_{\mathrm{a}}}{2 D_{j, \mathrm{a}}}+\frac{\Delta z_{b}}{2 D_{j, b}}\left(\frac{B_{j-1} \theta_{j-1}+\varepsilon_{j-1}}{B_{j} \theta_{j}}\right), \\
r_{j} & =\frac{\Delta z_{j+1}}{2 D_{j+1}}+\frac{\Delta z_{b}}{2 D_{j, b}}+\frac{\Delta z_{\mathrm{a}}}{2 D_{j, \mathrm{a}}}\left(\frac{B_{j+1} \theta_{j+1}}{B_{j} \theta_{j}+\varepsilon_{j}}\right), \\
a & =\frac{\Delta z_{\mathrm{a}}}{\Delta z_{j}}+\frac{\Delta z_{b}}{\Delta z_{j}}\left(\frac{B_{j-1} \theta_{j-1}+\varepsilon_{j-1}}{B_{j} \theta_{j}}\right), \\
b & =\frac{\Delta z_{\mathrm{a}}}{\Delta z_{j}}\left(\frac{B_{j+1} \theta_{j+1}}{B_{j} \theta_{j}+\varepsilon_{j}}\right)+\frac{\Delta z_{b}}{\Delta z_{j}} .
\end{aligned}
$$

$\Delta z_{\mathrm{a}}$ is the distance from the wetting front to the upper boundary of numerical node $j$, and $\Delta z_{b}$ is the distance from the wetting front to the lower boundary of numerical node $j$. Equations (9)-(11) are used to solve the diffusion of aqueous and gaseous tracer, where we used $C_{j}=\theta_{j} C_{\mathrm{w}, j}+\varepsilon_{j} C_{\mathrm{g}, j}$ and assumed that transport of the adsorbed phase of the tracer (if it does exist) can be considered separately as justified in the formulation of Eq. (8). When the water table level overlaps the grid interface, Eqs. (9)-(11) become identical to the relationships used in Riley et al. (2011).

\subsubsection{Advective transport}

In order to be consistent with the way that CLM4 updates soil water content, the advection operator is next solved for soil aqueous phase tracers:

$\theta \frac{\partial C_{\mathrm{w}}}{\partial t}=-\frac{\partial u_{\mathrm{w}} C_{\mathrm{w}}}{\partial z}-\left(q_{\mathrm{T}}+\frac{\partial \theta}{\partial t}\right) C_{\mathrm{w}}$.

Currently, gas advection is accounted for by a pressure adjustment approach (e.g., Tang et al., 2010), such that the gas column is always hydrostatically stable. In future work we will incorporate an explicit Darcy solver for gaseous advection.

Since the soil moisture and water fluxes are updated before the advection of the aqueous tracers, Eq. (12) is solved as

$\frac{\theta^{n+1}}{\Delta t}\left(C_{\mathrm{w}}^{n+1}-C_{\mathrm{w}}^{n}\right)=U^{n}-\left(q_{\mathrm{T}}+\frac{\partial \theta}{\partial t}\right)^{n+1} C_{\mathrm{w}}^{n+1}$,

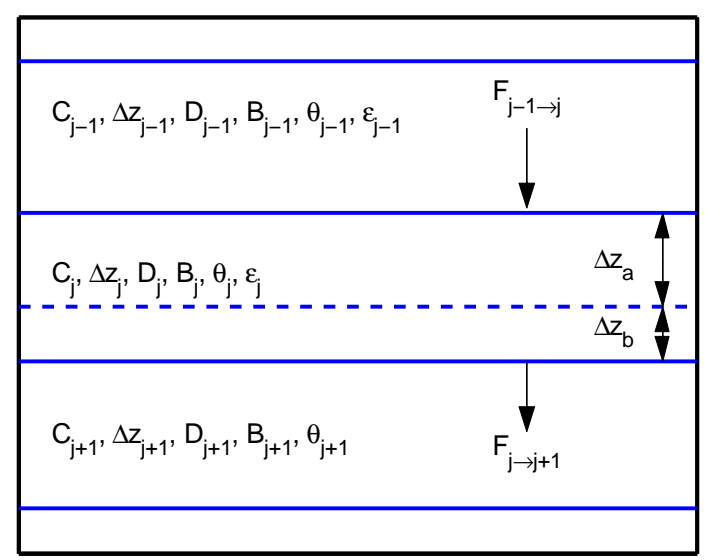

Fig. 2. Numerical model configuration when the water table (dashed line) is inside a grid layer. Subscript " $a$ " indicates variables that are defined above the water table (or wetting front), and subscript " $b$ " indicates variables that are defined below the water table (or wetting front). Three grid layers are considered: $j-1, j$, and $j+1$. Relevant symbols are defined in the text.

where $U^{n}$ is the forward-in-time upstream discretization (Tremback et al., 1987) of the advection term in Eq. (12). In the model, whether a particular aqueous tracer is allowed to move with the transpiration flux $q_{\mathrm{T}}$ is set prior to runtime. As such, CLM4-BeTR provides a method to assess the importance of transpiration-induced tracer fluxes. For instance, the movement of soil $\mathrm{CO}_{2}$ into roots and xylem water (Teskey et al., 2008) or nutrient uptake in the transpired water flow to meet the plant's nutrient demand (e.g., Plhak, 2003) can be explored with this model structure by further considering relevant storage pools in plant.

\subsubsection{Tracer movement in snow}

The aqueous tracer movement associated with snow accumulation and melt are computed in a similar way as for aerosols in CLM4 (Oleson et al., 2010). CLM4 assumes aerosols are uniformly sorbed to the snow particles and redistributes them according to the change of snow mass, while assuming no diffusive movement of those aerosols. Besides considering snow sorption, CLM4-BeTR also considers tracer movement through both advection and diffusion, and uses the fast equilibrium approximation to partition the relative mass of a tracer in its different phases in the snow.

\subsection{Boundary conditions and surface flux calculation}

The top boundary condition for advection is determined by the flux from atmospheric precipitation and canopy dripping, either in the form of snowfall or rainfall, or both. We modeled the soil-atmosphere diffusive exchange using the twolayer model that has been widely used for parameterizing bidirectional soil-atmosphere trace gas exchange (e.g., Wu et 


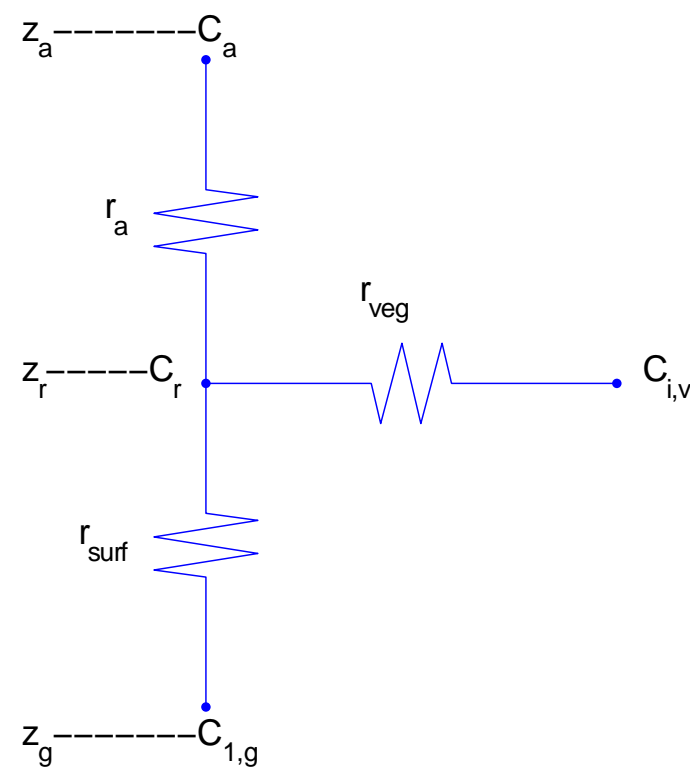

Fig. 3. The relationship between gas concentrations at different levels (i.e., $z_{g}$ is the center of the top soil control volume, $z_{r}$ is the apparent sink level, and $z_{\mathrm{a}}$ is the atmosphere reference height) and their relevant resistances. The relationships are explained in text.

al., 2009) and latent heat flux (in CLM4; see Oleson et al., 2010), which is described below.

The two-layer model (Fig. 3) assumes no storage of tracer mass inside the canopy air and that between the soil surface and the level of apparent sink $\left(z_{r}\right)$, which leads to a diagnosed gaseous tracer concentration at the level of the apparent sink:

$C_{r}=r_{\mathrm{T}}\left(\frac{C_{1, \mathrm{~g}}}{r_{\mathrm{surf}}}+\frac{C_{\mathrm{i}, v}}{r_{\mathrm{veg}}}+\frac{C_{\mathrm{a}}}{r_{\mathrm{a}}}\right)$,

where $C_{\mathrm{i}, v}$ (mol tracer $\mathrm{m}^{-3}$; subscript i means inside leaf) is the weighted leaf internal gas concentration (including contributions from sunlit and shaded leaves, see Appendix B) of a given tracer; $C_{\mathrm{a}}\left(\mathrm{mol}\right.$ tracer $\left.\mathrm{m}^{-3}\right)$ is the atmospheric gas concentration; and $C_{1, \mathrm{~g}}\left(\mathrm{~mol}\right.$ tracer $\left.\mathrm{m}^{-3}\right)$ is the top soil control volume gas concentration. The surface $\left(r_{\text {surf }}\right)$, vegetation $\left(r_{\text {veg }}\right)$, and weighted bulk $\left(r_{\mathrm{T}}\right)$ resistances $\left(\mathrm{s} \mathrm{m}^{-1}\right)$ are defined as

$$
\begin{aligned}
r_{\mathrm{surf}} & =\left(r_{\mathrm{a}, \mathrm{s}}+r_{\mathrm{b}, \mathrm{s}}+r_{\mathrm{s}, \mathrm{s}}\right)+\frac{\Delta z_{1}}{2 D_{1}\left(B_{1} \theta_{1}+\varepsilon_{1}\right)}, \\
r_{\mathrm{veg}} & =r_{\mathrm{b}, v}+r_{\mathrm{s}, v}, \\
r_{\mathrm{T}} & =\left(\frac{1}{r_{\mathrm{surf}}}+\frac{1}{r_{\mathrm{veg}}}+\frac{1}{r_{\mathrm{a}}}\right)^{-1},
\end{aligned}
$$

where $r_{\mathrm{a}, \mathrm{s}}\left(\mathrm{s} \mathrm{m}^{-1}\right)$ is the aerodynamic resistance inside the canopy air; $r_{\mathrm{b}, \mathrm{s}}\left(\mathrm{s} \mathrm{m}^{-1}\right)$ is the soil surface laminar boundary layer resistance; $r_{\mathrm{s}, \mathrm{s}}\left(\mathrm{s} \mathrm{m}^{-1}\right)$ is the resistance due to surface litter (Sakaguchi and Zeng, 2009); $r_{\mathrm{a}}\left(\mathrm{s} \mathrm{m}^{-1}\right)$ is the aerodynamic resistance above the canopy; $r_{\mathrm{b}, v}\left(\mathrm{~s} \mathrm{~m}^{-1}\right)$ is the leaf boundary layer resistance; $r_{\mathrm{s}, v}\left(\mathrm{~s} \mathrm{~m}^{-1}\right)$ is the weighted stomatal resistance (Eq. B5 in Appendix B) that includes contributions from sunlit and shaded leaves; and $\Delta z_{1}(\mathrm{~m}), \theta_{1}$ ( $\mathrm{m}^{-3}$ water $\mathrm{m}^{-3}$ soil), $\varepsilon_{1}\left(\mathrm{~m}^{3}\right.$ air $\mathrm{m}^{-3}$ soil), and $D_{1}\left(\mathrm{~m}^{2} \mathrm{~s}^{-1}\right)$ are, respectively, the thickness, water filled porosity, air filled porosity, and bulk tracer diffusivity defined for the top soil control volume. A derivation of Eq. (15) is provided in Tang and Riley (2012).

The diffusive flux at the soil surface, $F_{\text {surf }}$ (mol tracer $\mathrm{m}^{-2} \mathrm{~s}^{-1}$, positive upward), is

$$
\begin{gathered}
F_{\text {surf }}=-\frac{C_{r}-C_{1, \mathrm{~g}}}{r_{\text {surf }}}= \\
-\frac{r_{\mathrm{T}}}{r_{\text {surf }}}\left(\frac{C_{\mathrm{i}, v}}{r_{\mathrm{veg}}}+\frac{C_{\mathrm{a}}}{r_{\mathrm{a}}}\right)+\frac{C_{1, \mathrm{~g}}}{r_{\text {surf }}}\left(1-\frac{r_{\mathrm{T}}}{r_{\text {surf }}}\right) .
\end{gathered}
$$

For a non-vegetated bare soil, $r_{\mathrm{veg}}$ is set to infinity and $r_{\mathrm{a}, \mathrm{s}}$ is set to zero, which leads to the diffusive flux up from the surface:

$F_{\text {surf }}=-\frac{C_{\mathrm{a}}-C_{1, \mathrm{~g}}}{r_{\mathrm{a}}+r_{\text {surf }}}$.

The diffusive efflux from the vegetation $F_{\text {veg }}$ $\left(\mathrm{mol}\right.$ tracer $\left.\mathrm{m}^{-2} \mathrm{~s}^{-1}\right)$ is

$$
\begin{gathered}
F_{\text {veg }}=-\frac{C_{r}-C_{\mathrm{i}, v}}{r_{\mathrm{veg}}}= \\
-\frac{r_{\mathrm{T}}}{r_{\mathrm{veg}}}\left(\frac{C_{1, \mathrm{~g}}}{r_{\mathrm{surf}}}+\frac{C_{\mathrm{a}}}{r_{\mathrm{a}}}\right)+\frac{C_{\mathrm{i}, v}}{r_{\mathrm{veg}}}\left(1-\frac{r_{\mathrm{T}}}{r_{\mathrm{veg}}}\right) .
\end{gathered}
$$

The total diffusive flux of the tracer, $F_{\text {tot }}$ (mol tracer $\mathrm{m}^{-2} \mathrm{~s}^{-1}$ ), exchanging with the atmosphere is

$$
F_{\text {tot }}=\frac{r_{\mathrm{T}}}{r_{\mathrm{a}}}\left(\frac{C_{1, \mathrm{~g}}}{r_{\mathrm{surf}}}+\frac{C_{\mathrm{i}, v}}{r_{\mathrm{veg}}}\right)-\frac{C_{\mathrm{a}}}{r_{\mathrm{a}}}\left(1-\frac{r_{\mathrm{T}}}{r_{\mathrm{a}}}\right) .
$$

The radiation boundary condition (i.e., tracer only advects along the direction of water flow; e.g., see Raymond and Kuo, 1984) is applied at the lower boundary. However, since CLM4 has no representation of tracer concentrations in groundwater (Oleson et al., 2010), no tracer, except water, is allowed to enter the hydrologically active soil from the aquifer through recharge.

\subsection{Tracer flux diagnostics}

CLM4-BeTR diagnoses tracer fluxes along different physical pathways explicitly. Tracers from dry and wet deposition to the soil surface are directly added to the first soil (or snow) layer. During snow melting, the aqueous tracers are moved inside the snow layers consistently with liquid water flow. The total aqueous fluxes reaching the soil surface are partitioned into tracer infiltration and run-off loss in accordance with the partitioning of infiltration and surface run-off of liquid water. 
To compute horizontal tracer fluxes inside the soil associated with surface runoff, we assumed that aqueous tracers in the first two soil layers (totaling $4.5 \mathrm{~cm}$ thick) are in equilibrium with those in the runoff water. The tracer concentrations in these top two soil layers are then updated accordingly. This approach is used as an approximation due to the omission of a prediction of the interactions of surface runoff on nearsurface soil moisture in CLM4. This approximation deserves more attention in subsequent model versions.

In order to compute the tracer loss through sub-surface drainage, the fraction of water removed from each hydrologically active layer is tracked explicitly. This fraction of water loss for a given soil layer is assumed to be equal to the fraction of aqueous tracer being lost, and is used to compute tracer loss from that specific soil layer.

In the current version of CLM4-BeTR, tracer fluxes through dew formation and drip from plant-interception are generically included following the approach CLM4 applies to represent these water fluxes, but are considered to be zero in the analyses that follow. For volatile tracers, the surface exchange through diffusion is computed using the gradient-based approach described in Sect. 2.3. Transport through parenchyma or arenchyma is formulated as in Riley et al. (2011). Ebullition is represented using the approach described in Tang et al. (2010), which considers the pressure contributed from different volatile tracers while imposing no gas volume theresholds as done in other studies (e.g., Wania et al., 2010; Riley et al., 2011).

Since the physical parameters to drive diffusive and advective transport are formulated as functions of soil moisture and temperature, the physical effects of the freeze-thaw cycle are considered explicitly during tracer transport. The ice fraction provided by the soil physics module is used to determine the effective porosity of the aqueous and gaseous phases. Whether a given dissolved tracer can be locked into ice is a property that needs to be set prior to runtime. When applied, the change in ice fraction over a time step is used to parameterize the fraction of the dissolved tracer locked into, or lost from, the ice. When the surface soil layer is completely frozen, tracer diffusion to the atmosphere is suppressed. This model feature (not applied in the analyses here) allows us to explore the effect of freeze-thaw cycles on substrate and nutrient availability for plant roots and soil microorganisms, which we will explore in future studies. However, the current version of the model resolves the episodic gas emissions due to changes in effective soil porosity following freeze-thaw events (e.g., Mastepanov et al., 2008).

\section{Model evaluation and example applications}

Below we first describe the strategies used to evaluate CLM4-BeTR, including a comparison of numerical and analytical solutions and a comparison of model outputs with site-level measurements at Harvard Forest (http://harvardforest.fas.harvard.edu/). Then we present a simple application to show how the tracer tracking capability can provide new insights into interpretation of tracer concentration and flux measurements and their representation in large-scale biogeochemical models such as CLM4.

\subsection{Evaluation against analytical solutions}

A comparison between the numerical and analytical solutions was conducted to evaluate the accuracy of the 1-D transport simulator integrated in CLM4-BeTR. We used two different analytical solutions to evaluate the code. The two analytical solutions satisfy the 1-D reactive transport equation:

$\frac{\partial C}{\partial t}=\frac{\partial}{\partial z}\left(D \frac{\partial C}{\partial z}\right)-u \frac{\partial C}{\partial z}$,

with their respective initial conditions and boundary conditions. Here, $D$ is diffusivity, and $u$ is advection velocity (positive downward). In all comparisons between the numerical and analytical solutions, the diffusivity $D$ was set to $10^{-6} \mathrm{~m}^{2} \mathrm{~s}^{-1}$ and the advection velocity $u$ was set to $10^{-7} \mathrm{~m} \mathrm{~s}^{-1}$ (equivalent to an annual drainage of $3.7 \mathrm{~m} \mathrm{yr}^{-1}$ ).

For the first analytical solution, a pulse tracer input is imposed at the top of a 1-D column of length $L$, resulting in the tracer concentration $C\left(\mathrm{~mol} \mathrm{~m}^{-3}\right)$ :

$$
\begin{aligned}
& C=\frac{1}{2} \operatorname{erfc}\left(\frac{z-u t}{2 \sqrt{D t}}\right)+\frac{1}{2} \exp \left(\frac{u z}{D}\right) \operatorname{erfc}\left(\frac{z+u t}{2 \sqrt{D t}}\right) \\
& +\left[1+\frac{u}{2 D}(2 L-z+u t)\right] \times \exp \left(\frac{u L}{D}\right) \operatorname{erfc}\left(\frac{2 L-z+u t}{2 \sqrt{D t}}\right) \\
& -\sqrt{\frac{u^{2} t}{\pi D}} \exp \left[\frac{u L}{D}-\frac{(2 L-z+u t)^{2}}{4 D t}\right],
\end{aligned}
$$

where $\operatorname{erfc}(x)$ is the complementary error function of $x$. For the comparisons, we set $L=42.10 \mathrm{~m}$, corresponding to the maximum depth of the temperature solution currently calculated in CLM4 (computed using Eqs. 6.5-6.7 in Oleson et al., 2010).

For the second analytical solution, the tracer concentration top boundary condition is

$$
\begin{aligned}
& C(z=0)=C_{0} \\
& +\sum_{i=1}^{2} A_{i} \exp \left(-\frac{u}{2 D}-\frac{\sqrt{2}}{4 D} \sqrt{u^{2}+\sqrt{u^{4}+16 D^{2} \omega_{i}^{2}}}\right) \sin \left(\omega_{i} t\right),
\end{aligned}
$$

which leads to the wave type analytical solution:

$$
\begin{aligned}
C= & C_{0}+\sum_{i=1}^{2} A_{i} \exp \left(-\frac{u}{2 D}-\frac{\sqrt{2}}{4 D} \sqrt{u^{2}+\sqrt{u^{4}+16 D^{2} \omega_{i}^{2}}}\right) \\
& \times \sin \left(\omega_{i} t-\frac{\sqrt{2} \omega_{i} z}{\sqrt{u^{2}+\sqrt{u^{4}+16 D^{2} \omega_{i}^{2}}}}\right)
\end{aligned}
$$

where $A_{i}, i=1,2,\left(\right.$ mol tracer $\left.\mathrm{m}^{-3}\right)$ are the amplitudes and $\omega_{i}, i=1,2,\left(\mathrm{~s}^{-1}\right)$ are the frequencies. For the numerical comparison, we set $C_{0}=12 / 23 \mathrm{moltracer} \mathrm{m}^{-3}, A_{1}=$ 
9/23 mol tracer $\mathrm{m}^{-3}, \quad A_{2}=2 / 23$ mol tracer $\mathrm{m}^{-3}, \quad \omega_{1}=$ $2 \pi /(365 \times 86400) \mathrm{s}^{-1}$ and $\omega_{2}=2 \pi / 86400 \mathrm{~s}^{-1}$. The values of parameters $C_{0}, A_{1}$, and $A_{2}$ are chosen to ensure that the maximum tracer concentration is $1 \mathrm{~mol} \mathrm{~m}^{-3}$.

\subsection{Single point evaluation at the Harvard Forest site}

We conducted a single point simulation at the Harvard Forest site with depth dependent $\mathrm{C}$ and $\mathrm{N}$ dynamics, which includes a vertically resolved soil biogeochemistry, a decomposition cascade, and nitrification and denitrification parameterization based on the CENTURY model (Parton et al., 1988; Del Grosso et al., 2000) for the site level evaluation. The tracer transport capability of CLM4-BeTR was used to evaluate the soil biogeochemistry, which provides the relevant tracer fluxes. To dynamically track the evolution of soil gas pressure, a total of six tracers were modeled: $\mathrm{N}_{2}, \mathrm{O}_{2}, \mathrm{Ar}, \mathrm{CO}_{2}^{\mathrm{X}}$, $\mathrm{N}_{2} \mathrm{O}$, and NO. Of the six tracers, $\mathrm{Ar}$ is the only one without soil sources or sinks and the others are driven by fluxes provided by the CENTURY biogeochemical formulation implemented in CLM4. We spun up the model for $1000 \mathrm{yr}$ using a repeating 57-yr (1948-2004) cycle of meteorological data extracted from the global dataset (Qian et al., 2006). Another 40 -yr simulation was then conducted, from which the average of the last $10 \mathrm{yr}$ of model output were compared with the measurements. The measurement data include $\mathrm{CO}_{2}$ effluxes (as derived ecosystem respiration) from the AmeriFlux dataset (level 4 ecosystem respiration flux data, from year 1992 to 2006; http://public.ornl.gov/ameriflux/dataproducts. shtml) and $\mathrm{CO}_{2}$ profiles collected at the site from June 1995 to December 2004 (Davidson et al., 2006). Given the uncertainties in meteorological forcing data, model parameterization, and site-model mismatch, we did not try to match the model predictions to the measurements, which would otherwise involve an intensive practice of data assimilation and uncertainty quantification of CLM4 that is beyond the scope of this study. Rather, we grouped the observed daily $\mathrm{CO}_{2}$ eddy flux observations into a single-year time series, and compared it with the simulated 10-yr mean daily fluxes and relevant statistics. Similarly, the measured $\mathrm{CO}_{2}$ profiles were grouped into monthly time steps to form a single-year time series to enable the comparison.

\subsection{Partitioning of surface $\mathrm{CO}_{2}$ fluxes with CLM4-BeTR}

To illustrate potential applications of CLM4-BeTR, we designed a tagged $\mathrm{CO}_{2}$ tracer simulation to visualize the relative contributions of different sources to the measured soil surface $\mathrm{CO}_{2}$ fluxes and soil $\mathrm{CO}_{2}$ concentrations. Specifically, using the initial conditions provided from the simulations described in Sect. 3.2, we represented the $\mathrm{CO}_{2}$ originating from three sources: root respiration, soil heterotrophic respiration, and atmospheric intrusion with three different tracers and tracked their temporal and spatial evolutions with CLM4-
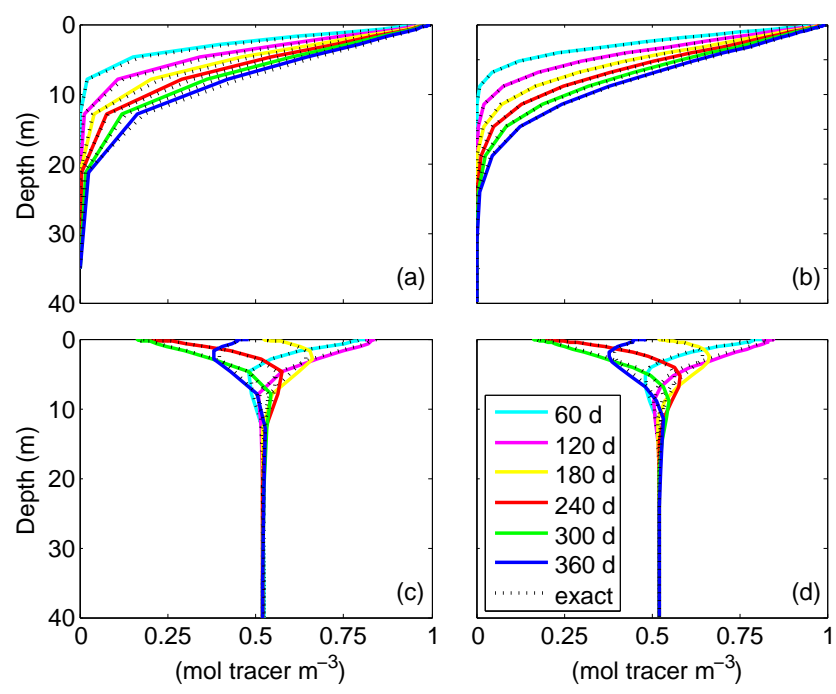

Fig. 4. Comparison between analytical (denoted as exact in the figure) and numerical solutions: (a) and (b) are for the pulse type solution described in Eq. (23); (c) and (d) are for the wave type solution described in Eq. (24). The left panels used the standard transformed exponential discretization for a soil column in CLM4 (see Eq. 6.5 in Oleson et al., 2010). The right panels used a refined discretization by doubling the number of nodes in the transformed exponential grid. See text for details of the comparison.

BeTR. This approach allowed us to partition the predicted soil surface $\mathrm{CO}_{2}$ fluxes into contributions from these three sources. We then analyzed whether these three sources have distinct signals from the soil surface $\mathrm{CO}_{2}$ effluxes and soil $\mathrm{CO}_{2}$ concentrations measured in the field. Such an analysis would also be useful to benchmark the isotopic partitioning of $\mathrm{CO}_{2}$ fluxes from different belowground respiration components, which is left for our future studies.

\section{Results and discussion}

\subsection{Evaluation against analytical solutions}

Comparisons between numerical and analytical solutions indicate the 1-D transport code accurately (root mean square errors are less than 0.01 for all cases) represented tracer transport for both the pulse and wave boundary condition simulations using the CLM4 standard vertical discretization and time step (Fig. 4a and c). Refining the vertical resolution (i.e., halving the grid size in the transformed exponential coordinate system, see Eq. 6.5 in Oleson et al., 2010) indicated that numerical convergence slightly improved (Fig. $4 \mathrm{~b}$ and d), but the improvement is small considering the extra computation and storage required. These results indicate the transport algorithm for CLM4-BeTR has good accuracy for these test cases. We conclude that the default CLM4 vertical grid structure and time-step $(30 \mathrm{~min})$ is sufficient to produce reasonable model simulations. 


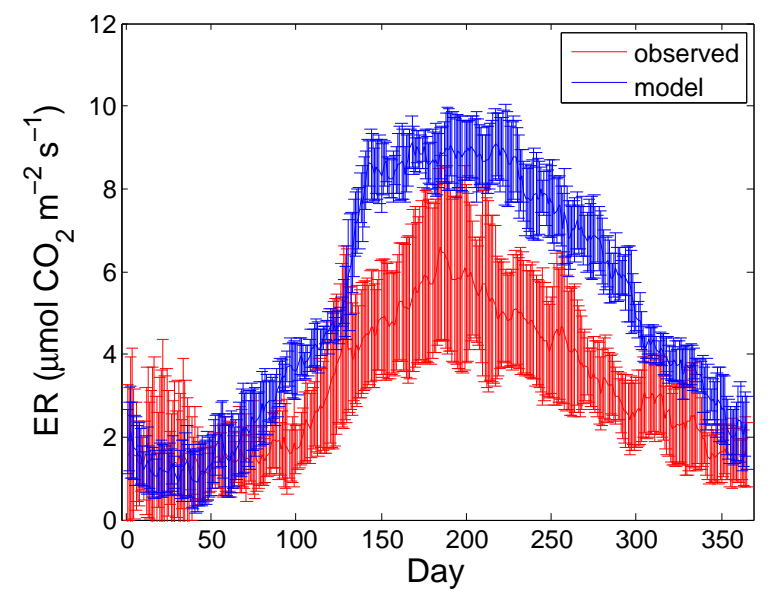

Fig. 5. Comparison between flux data and model simulated ecosystem respiration at the Harvard Forest site. The error bars indicate the one-standard deviation with respect to the mean. The observed data is derived from the level 4 eddy flux data at the site.

\subsection{Single point evaluation at the Harvard Forest site}

Simulated mean seasonal cycle of ecosystem respiration was generally in good agreement with the data derived from tower eddy flux measurements (Fig. 5). Starting from April (day 91), the model simulated larger ecosystem $\mathrm{CO}_{2}$ respiration fluxes than observed, though predicted GPP (gross primary production) is close to the measurements (with a linear fitting $x=0.88 y-0.8780\left(\mu \mathrm{mol} \mathrm{CO} \mathrm{Cm}^{-2} \mathrm{~s}^{-1}\right)$, where $x$ represents simulated GPP, and $y$ represents the observed data; data not shown). The overestimation in ecosystem respiration could be from any of the predicted respiratory components, including above ground autotrophic respiration, root autotrophic respiration, and soil heterotrophic respiration.

We next integrated the predicted belowground $\mathrm{CO}_{2}$ production (i.e., soil respiration, which equals heterotrophic respiration plus autotrophic root respiration) rate with the transport module in CLM4-BeTR to calculate soil-gas $\mathrm{CO}_{2}$ concentrations (Fig. 6). The predicted soil $\mathrm{CO}_{2}$ concentrations were generally higher than observed from April through June, in relatively good agreement with observations from July through September, and higher than observed from October through December. It is not clear whether the overestimation in soil $\mathrm{CO}_{2}$ concentrations resulted from an overestimation of the $\mathrm{CO}_{2}$ production rate in soil heterotrophic respiration or in root autotrophic respiration, or insufficient transport due to incorrect physical forcing, or even some combination that varied with time. However, analyses indicated that the simulated soil temperature was in good agreement with measurement at all four-observation depths $(6,10,33$, and $60 \mathrm{~cm})$ where the soil air samples were taken (Fig. S1). The simulated soil moisture was higher than observed throughout most of the year (Fig. S2). Hence, according to the way that soil moisture affects tracer transport and
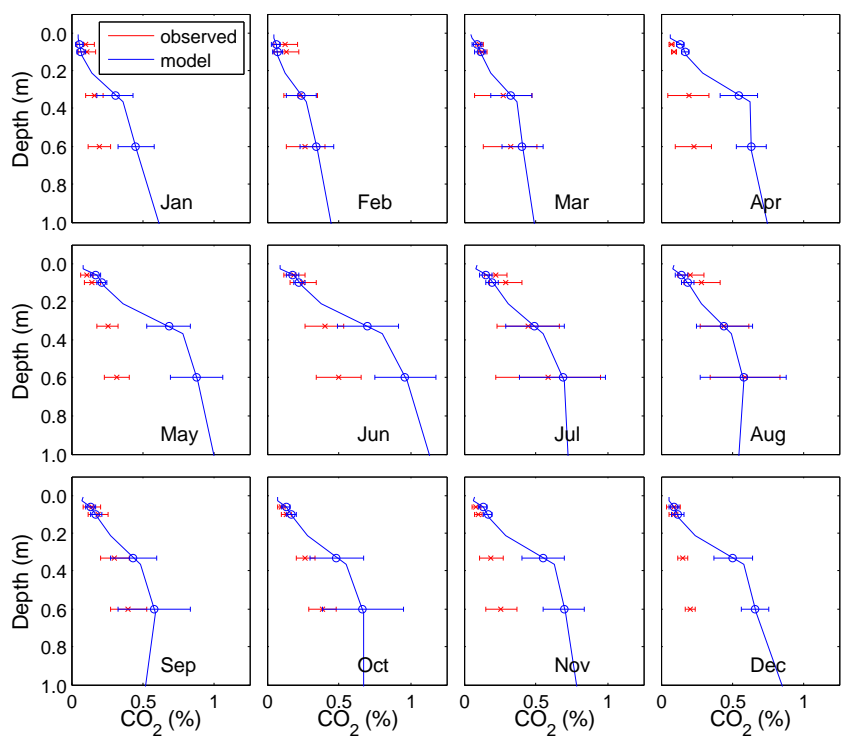

Fig. 6. Comparison between measured and simulated soil $\mathrm{CO}_{2}$ profiles for a whole seasonal cycle. Both the measurement and model simulation were aggregated monthly for the comparison. The error bar indicates the one-sigma standard deviation derived from all the data points in a given month.

organic matter decomposition (Andren and Paustian, 1987) in the model, a reasonable hypothesis is that (1) tracer transport calculations were forced by incorrect soil water dynamics and (2) the soil heterotrophic respiration was overestimated, given that oxygen and organic matter availability were never the limiting factor for soil heterotrophic respiration. Further, a mass budget analysis of the belowground $\mathrm{CO}_{2}$ dynamics indicated that, at this site, the difference between annual surface efflux and belowground production of $\mathrm{CO}_{2}$ is small, and loss through surface and subsurface runoff is less than $1 \%$ of the total $\mathrm{CO}_{2}$ from soil respiration.

\subsection{Partitioning surface $\mathrm{CO}_{2}$ fluxes}

We found the three predicted $\mathrm{CO}_{2}$ sources (soil heterotrophic respiration, root respiration, and atmospheric $\mathrm{CO}_{2}$ intrusion) differ distinctly in contributing to the overall soil surface $\mathrm{CO}_{2}$ efflux (Fig. 7a). The atmospheric $\mathrm{CO}_{2}$ intrusion (denoted by Air) contributed a negligible amount (being two orders of magnitude smaller than the other two sources), indicating, as expected, that the surface $\mathrm{CO}_{2}$ efflux was dominated by belowground biogeochemical production. In this simulation, the $\mathrm{CO}_{2}$ produced from soil heterotrophic respiration dominated the total surface efflux, particularly in the non-growing season, when autotrophic root respiration diminished due to reduced vegetation productivity. In addition, due to a tight coupling with soil physics, soil heterotrophic $\mathrm{CO}_{2}$ production was more temporally variable than root autotrophic respiration. However, we are not sure if this behavior is close to what actually occurred in the field. 

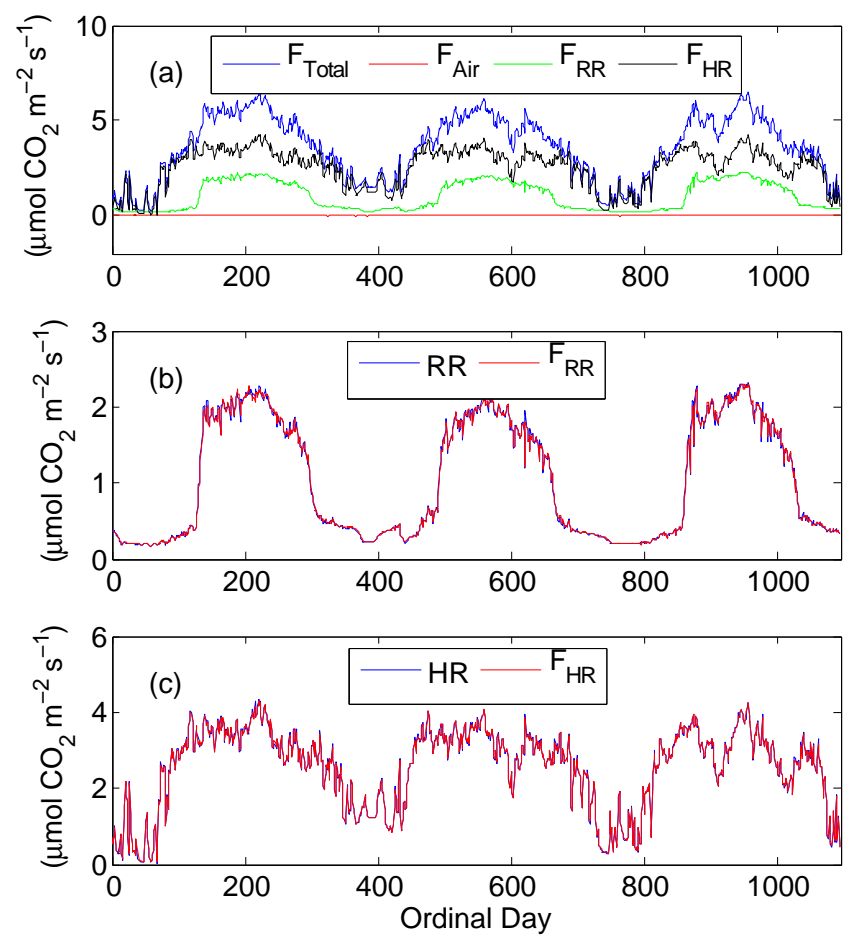

Fig. 7. A comparison of the simulated component-wise soil surface $\mathrm{CO}_{2}$ effluxes and their belowground production rates. $F_{\text {Air }}, F_{\mathrm{RR}}$, and $F_{\mathrm{HR}}$ are, respectively, the surface $\mathrm{CO}_{2}$ effluxes corresponding to atmospheric $\mathrm{CO}_{2}$ (Air), production from autotrophic root respiration $(\mathrm{RR})$, and soil heterotrophic respiration $(\mathrm{SR}) . F_{\text {Total }}$ is the sum of $F_{\mathrm{Air}}, F_{\mathrm{RR}}$, and $F_{\mathrm{HR}}$.

At the daily time step, small yet significant discrepancies existed between simulated surface $\mathrm{CO}_{2}$ effluxes and soil respiration (Fig. $7 \mathrm{~b}$ and c). However, more significant discrepancies were identified when the surface $\mathrm{CO}_{2}$ effluxes and soil respiration were compared at the hourly time scale (Figs. 8a-d and S3). In the growing season (from 1 May to 31 October), we found hourly soil surface $\mathrm{CO}_{2}$ effluxes were often different from the belowground $\mathrm{CO}_{2}$ production rate (Fig. S3b). We found distinct differences between the surface $\mathrm{CO}_{2}$ efflux $F_{\mathrm{SR}}\left(\mu \mathrm{mol} \mathrm{CO} \mathrm{Cm}^{-2} \mathrm{~s}^{-1}\right)$ and belowground soil respiration SR $\left(\mu \mathrm{mol} \mathrm{CO} \mathrm{Cm}^{-2} \mathrm{~s}^{-1}\right)$, mostly with the $F_{\mathrm{SR}}$ higher than SR in the daytime and vice versa in the nighttime during the growing season (Fig. 8b-d). This diurnal variability in the difference between $F_{\mathrm{SR}}$ and SR resulted in a slight asymmetry (statistically significant with $p<0.01$ ) in the histogram of the relative differences (defined as $\left.\left(F_{\mathrm{SR}}-\mathrm{SR}\right) / F_{\mathrm{SR}} \times 100 \%\right)$ for the growing season (Figs. 8e and S4). The relative difference at the hourly scale could be as much as $20 \%$ during the growing season, and up to $80 \%$ during the winter, when freeze-thaw driven episodic emissions occurred (e.g., the peak emission on day 30 in Fig. S3a). When averaged over daily time steps, however, the differences between the surface $\mathrm{CO}_{2}$ effluxes and belowground production were much smaller and showed a
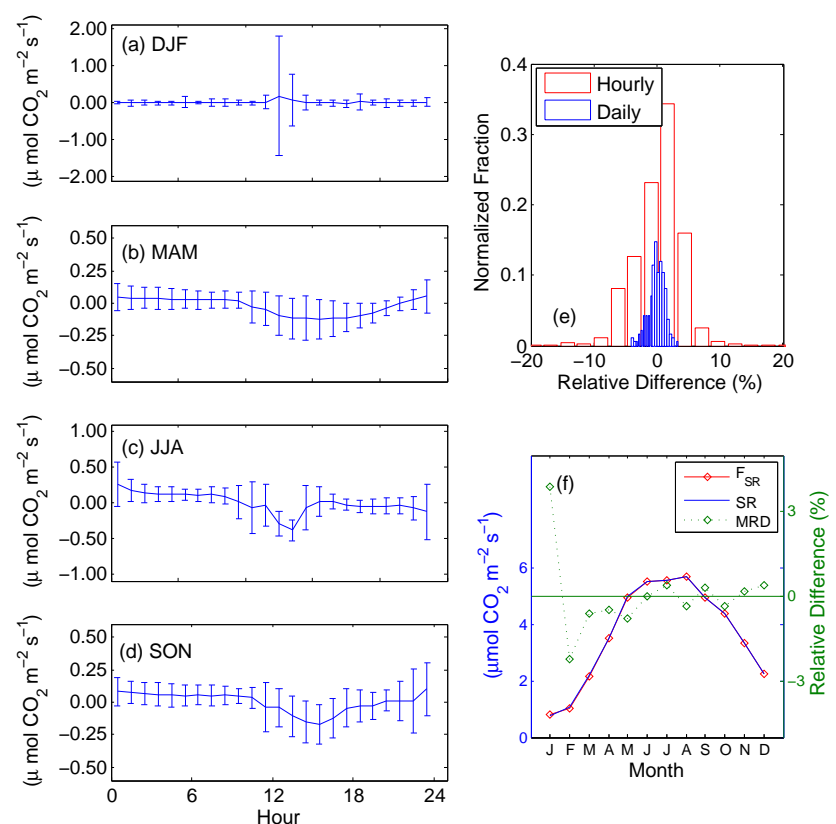

Fig. 8. A comparison of surface $\mathrm{CO}_{2}$ effluxes and their production rates at different temporal scales. (a), (b), (c), and (d) show the hourly difference between surface $\mathrm{CO}_{2}$ efflux $\left(F_{\mathrm{SR}}\right)$ and their corresponding soil respiration (SR) averaged for different threemonth periods. (e) Histograms of the relative differences $\left(\left(F_{\mathrm{SR}}-\right.\right.$ $\left.\mathrm{SR}) / F_{\mathrm{SR}} \times 100 \%\right)$ at hourly and daily time steps. (f) Comparison of monthly time step time series of surface $\mathrm{CO}_{2}$ effluxes and soil respiration. MRD represents the monthly relative difference. See text for details of the analysis.

more symmetric distribution around the mean zero (Fig. 8e), supporting the finding that the temporal averaging to time scales larger than 24-h could suppress the strong small time step signals in the measured $\mathrm{CO}_{2}$ surface efflux (Fig. 7). Nevertheless, the significant differences at the hourly time scale implied potential problems associated with the common approach used to infer GPP from eddy covariance NEE (net ecosystem exchange) measurements (Desai et al., 2008; Lasslop et al., 2010). These differences also challenge the assumption that below ground $\mathrm{CO}_{2}$ production equals surface $\mathrm{CO}_{2}$ efflux that has been long held in parameterizing the soil respiration model using field measured surface $\mathrm{CO}_{2}$ efflux data.

Grouping the relative differences into a monthly time step showed there were seasonally systematic biases. In particular, the surface $\mathrm{CO}_{2}$ effluxes tended to be smaller than belowground production during the thaw period, and vice versa during the freezing period (Fig. 8f). To better understand these seasonally dependent biases, we analyzed hourly time step model predictions for four different three-day periods: the end of January, early May, late July, and late October (Fig. 9). In the thaw season, $\mathrm{CO}_{2}$ loss through surface and belowground drainage, as well as increased soil gas storage capacity, made the surface $\mathrm{CO}_{2}$ efflux smaller than the 

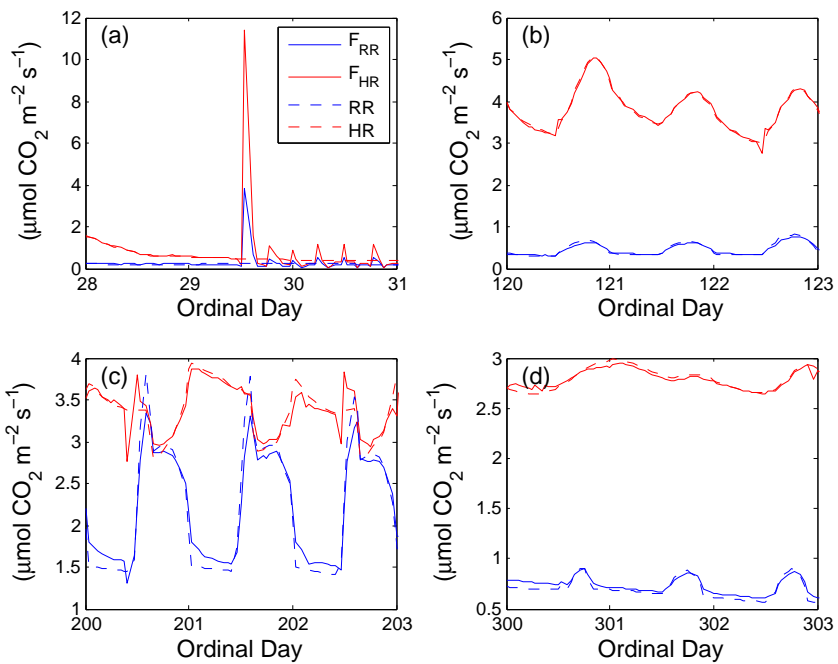

Fig. 9. Comparison of simulated surface $\mathrm{CO}_{2}$ efflux with their corresponding belowground production rates at four different time periods. $F_{\mathrm{RR}}$ is the surface $\mathrm{CO}_{2}$ efflux corresponding to that produced from autotrophic root respiration RR. $F_{\mathrm{HR}}$ is the surface $\mathrm{CO}_{2}$ efflux corresponding to that produced from soil heterotrophic respiration HR.

total belowground production rates. However, when temperatures were below freezing (days 28-31 and 300-303), the loss through drainage diminished and the soil gas storage capacity decreased, such that very strong episodic $\mathrm{CO}_{2}$ emissions can occur during the short-term thaw event between two consecutive freezing events or at the start of the thaw season. Such episodic emissions can be three to four times higher than the $\mathrm{CO}_{2}$ effluxes during the peak-growing season (Figs. S3a and 9a), and 20 or more times higher than the actual belowground $\mathrm{CO}_{2}$ production rate. Field measurements are needed to assess whether these predictions are realistic, although similar signals have been observed for $\mathrm{CH}_{4}$ fluxes in inundated soils in Sanjiang Plain, Northeast China (Song et al., 2012).

In accordance with the distinct temporal patterns of $\mathrm{CO}_{2}$ production rates from soil heterotrophic respiration and autotrophic root respiration (Fig. 7), the resulting $\mathrm{CO}_{2}$ concentrations from these two sources also showed distinct temporal patterns (Fig. 10). The $\mathrm{CO}_{2}$ produced from soil heterotrophic respiration persisted at higher levels over a longer fraction of the year than $\mathrm{CO}_{2}$ from root respiration. However, due to the physical transport of the $\mathrm{CO}_{2}$ in the soil profile, we found that the location of high $\mathrm{CO}_{2}$ concentrations usually differed from the $\mathrm{CO}_{2}$ production hot spots. In addition, when an incorrect top boundary condition or a different root profile was used, the simulated surface $\mathrm{CO}_{2}$ effluxes would not change significantly although the soil $\mathrm{CO}_{2}$ concentrations would drastically change (results not shown). These finding indicate that field soil $\mathrm{CO}_{2}$ concentration measurements can provide additional constraints on belowground biogeochemistry besides that provided from surface $\mathrm{CO}_{2}$ efflux measurements.

\section{Summary}

In this study, we presented methods, testing, and an application of CLM4-BeTR, a general multi-phase reactive transport model integrated in CLM4. The model is designed to tightly couple depth-dependent biogeochemistry and physics, to use a hierarchy of biogeochemistry models with different structural complexities, and to readily couple with atmospheric chemistry and physics modules. The comparison with analytical solutions showed the transport calculations were accurate with the default CLM4 time-step and vertical grid structure. An evaluation of modeled surface $\mathrm{CO}_{2}$ effluxes and soil $\mathrm{CO}_{2}$ profiles indicates that the model was able to reasonably capture the seasonal dynamics of soil surface $\mathrm{CO}_{2}$ effluxes and soil $\mathrm{CO}_{2}$ concentrations, subject to the uncertainties associated with the measurements and model forcings. The component-wise $\mathrm{CO}_{2}$ tracer transport experiment indicated that there are timescale-dependent differences between the surface $\mathrm{CO}_{2}$ effluxes and the corresponding belowground $\mathrm{CO}_{2}$ production rates. These results indicate that soil $\mathrm{CO}_{2}$ concentration profile measurements provide additional information beyond soil surface $\mathrm{CO}_{2}$ efflux measurements to constrain terrestrial biogeochemistry models. In future studies, we will present further developments associated with CLM4-BeTR, such as explicit carbon and nitrogen transport, isotope transport and microbial dynamics, that enable a comprehensive and mechanistically-based evaluation of atmosphere-biosphere interactions, involving both physical and chemical feedbacks.

\section{Appendix A}

\section{Computing the diffusivities}

Following the approach by Moldrup et al. (2003), the effective diffusivity for aqueous tracer is computed as

$D_{\mathrm{w}}=D_{\mathrm{w}}^{*} \theta\left(\frac{\theta}{\phi}\right)^{\kappa / 3-1}$.

The effective diffusivity for gaseous tracer is computed as

$D_{\mathrm{g}}=D_{\mathrm{g}}^{*} \varepsilon\left(\frac{\varepsilon}{\phi}\right)^{3 / \kappa}$

Here, $\phi\left(\mathrm{m}^{3} \mathrm{~m}^{-3}\right)$ is the effective soil porosity, being equal to the soil porosity minus the space occupied by ice. $\kappa$ (unitless) is the shape parameter for the Clapp-Hornberger parameterization (Clapp and Hornberg, 1978). $D_{\mathrm{w}}^{*}$ is the aqueous tracer diffusivity in liquid water, and $D_{\mathrm{g}}^{*}$ is the gaseous tracer diffusivity in air. 


\section{Appendix B}

\section{Computing the weighted leaf internal gas concentration}

The flux (positive upward) over the sunlit leaf is

$F_{\text {sun }}=-r_{\text {sun }}^{-1}\left(C_{\mathrm{i}, \text { sun }}-C_{r}\right)$,

and the flux over the shaded leaf is

$F_{\text {sha }}=-r_{\text {sha }}^{-1}\left(C_{\mathrm{i}, \text { sha }}-C_{r}\right)$,

where the sunlit $\left(r_{\text {sun }}\right)$ and shaded $\left(r_{\text {sha }}\right)$ resistance $\left(\mathrm{s} \mathrm{m}^{-1}\right)$ are functions of leaf (stem) area index and leaf boundary layer resistance (see Sect. 5.3 in Oleson et al., 2010).

Then the total flux over the canopy is

$$
\begin{aligned}
& F_{\text {veg }}=F_{\text {sun }}+F_{\text {sha }} \\
& =-\left(r_{\text {sun }}^{-1}+r_{\text {sha }}^{-1}\right)\left(\frac{r_{\text {sun }}^{-1} C_{\mathrm{i}, \text { sun }}+r_{\text {sha }}^{-1} C_{\text {i,sha }}}{r_{\text {sun }}^{-1}+r_{\text {sha }}^{-1}}-C_{r}\right),
\end{aligned}
$$

which gives the weighted leaf internal tracer concentration as

$C_{\mathrm{i}, v}=\frac{r_{\text {sun }}^{-1} C_{\mathrm{i}, \text { sun }}+r_{\text {sha }}^{-1} C_{\mathrm{i}, \text { sha }}}{r_{\text {sun }}^{-1}+r_{\text {sha }}^{-1}}$.

From Eq. (B3), the weighted stomatal resistance $r_{\mathrm{s}, v}$ $\left(\mathrm{s} \mathrm{m}^{-1}\right)$ is found as

$r_{\mathrm{s}, v}=\left(\frac{1}{r_{\mathrm{sun}}}+\frac{1}{r_{\mathrm{sha}}}\right)^{-1}$.

\section{Supplementary material related to this article is available online at: http://www.geosci-model-dev.net/6/ 127/2013/gmd-6-127-2013-supplement.pdf.}

Acknowledgements. This research was supported by the Director, Office of Science, Office of Biological and Environmental Research of the US Department of Energy under Contract No. DE-AC02-05CH11231 as part of their Regional and Global Climate Modeling Program. The authors appreciate Kathleen Savage and Eric Davidson at the Woods Hole Research Center for providing the soil $\mathrm{CO}_{2}$ profile data and soil moisture and temperature data at the Harvard Forest site.

Edited by: S. Arndt

\section{References}

Andren, O. and Paustian, K.: Barley Straw Decomposition in the Field - a Comparison of Models, Ecology, 68, 1190-1200, 1987.

Clapp, R. B. and Hornberger, G. M.: empirical equations for some soil hydraulic properties, Water Resour. Res., 14, 601-604, 1978.

Cox, P. M., Betts, R. A., Jones, C. D., Spall, S. A., and Totterdell, I. J.: Acceleration of global warming due to carbon-cycle feedbacks in a coupled climate model, Nature, 408, 184-187, doi:10.1038/35041539, 2000.

Davidson, E. A., Savage, K. E., Trumbore, S. E., and Borken, W. Vertical partitioning of $\mathrm{CO}_{2}$ production within a temperate forest soil, Glob. Change Biol., 12, 944-956, doi:10.1111/J.13652486.2005.01142.X, 2006.

Del Grosso, S. J., Parton, W. J., Mosier, A. R., Ojima, D. S., Kulmala, A. E., and Phongpan, S.: General model for $\mathrm{N}_{2} \mathrm{O}$ and $\mathrm{N}_{2}$ gas emissions from soils due to dentrification, Global Biogeochem. Cy., 14, 1045-1060, 2000.

Desai, A. R., Richardson, A. D., Moffat, A. M., Kattge, J., Hollinger, D. Y., Barr, A., Falge, E., Noormets, A., Papale, D., Reichstein, M., and Stauch, V. J.: Cross-site evaluation of eddy covariance GPP and RE decomposition techniques, Agr. Forest Meteorol., 148, 821-838, doi:10.1016/J.Agrformet.2007.11.012, 2008.

Eymard, R., Gutnic, M., and Hilhorst, D.: The finite volume method for Richards equation, Comput. Geosci., 3, 259-294, doi:10.1023/A:1011547513583, 1999.

Fang, C. and Moncrieff, J. B.: A model for soil $\mathrm{CO}_{2}$ production and transport 1: model development, Agr. Forest Meteorol., 95, 225-236, 1999.

Friedlingstein, P., Cox, P., Betts, R., Bopp, L., Von Bloh, W., Brovkin, V., Cadule, P., Doney, S., Eby, M., Fung, I., Bala, G., John, J., Jones, C., Joos, F., Kato, T., Kawamiya, M., Knorr, W. Lindsay, K., Matthews, H. D., Raddatz, T., Rayner, P., Reick, C., Roeckner, E., Schnitzler, K. G., Schnur, R., Strassmann, K., Weaver, A. J., Yoshikawa, C., and Zeng, N.: Climate-carbon cycle feedback analysis: Results from the C(4)MIP model intercomparison, J. Climate, 19, 3337-3353, 2006.

Grant, R. F.: Simulation-Model of Soil Compaction and RootGrowth, 1. Model Structure, Plant Soil, 150, 1-14, 1993.

Grant, R. F. and Roulet, N. T.: Methane efflux from boreal wetlands: Theory and testing of the ecosystem model Ecosys with chamber and tower flux measurements, Global Biogeochem. Cy., 16, 1054, doi:10.1029/2001gb001702, 2002

Gu, C. H., Maggi, F., Riley, W. J., Hornberger, G. M., Xu, T., Oldenburg, C. M., Spycher, N., Miller, N. L., Venterea, R. T., and Steefel, C.: Aqueous and gaseous nitrogen losses induced by fertilizer application, J. Geophys. Res.-Biogeo., 114, G01006, doi:10.1029/2008jg000788, 2009.

Heuvelink, G. B. M. and Pebesma, E. J.: Spatial aggregation and soil process modelling, Geoderma, 89, 47-65, 1999.

Intergovernmental Panel on Climate Change (IPCC), Climate Change 2007: The Physical Science Basis, Contribution of Working Group I to the Fourth Assessment Report of the Intergovernmental Panel on Climate Change, edited by: Solomon, S., Qin, D., Manning, M., Chen, Z., Marquis, M., Averyt, K. B., Tignor, M., and Miller, H. L., Cambridge University Press, Cambridge, United Kingdom and New York, NY, USA, 2007.

Jenkinson, D. S. and Coleman, K.: The turnover of organic carbon in subsoils, Part 2. Modelling carbon turnover, Euro. J. Soil Sci., 
59, 400-413, doi:10.1111/J.1365-2389.2008.01026.X, 2008.

Kaiser, C., Meyer, H., Biasi, C., Rusalimova, O., Barsukov, P., and Richter, A.: Conservation of soil organic matter through cryoturbation in arctic soils in Siberia, J. Geophys. Res.-Biogeo., 112, G02017, doi:10.1029/2006jg000258, 2007.

Kelly, R. H., Parton, W. J., Crocker, G. J., Grace, P. R., Klir, J., Korschens, M., Poulton, P. R., and Richter, D. D.: Simulating trends in soil organic carbon in long-term experiments using the century model, Geoderma, 81, 75-90, 1997.

Koven, C., Friedlingstein, P., Ciais, P., Khvorostyanov, D., Krinner, G., and Tarnocai, C.: On the formation of high-latitude soil carbon stocks: Effects of cryoturbation and insulation by organic matter in a land surface model, Geophys. Res. Lett., 36, L21501, doi:10.1029/2009g1040150, 2009.

Lasslop, G., Reichstein, M., Papale, D., Richardson, A. D., Arneth, A., Barr, A., Stoy, P., and Wohlfahrt, G.: Separation of net ecosystem exchange into assimilation and respiration using a light response curve approach: critical issues and global evaluation, Glob. Change Biol., 16, 187-208, doi:10.1111/J.13652486.2009.02041.X, 2010.

Maggi, F. and Porporato, A.: Coupled moisture and microbial dynamics in unsaturated soils, Water Resour. Res., 43, W07444, doi:10.1029/2006wr005367, 2007.

Maggi, F., Gu, C., Riley, W. J., Hornberger, G. M., Venterea, R. T., $\mathrm{Xu}, \mathrm{T}$., Spycher, N., Steefel, C., Miller, N. L., and Oldenburg, C. M.: A mechanistic treatment of the dominant soil nitrogen cycling processes: Model development, testing, and application, J. Geophys. Res., 113, G02016, doi:10.1029/2007jg000578, 2008.

Mastepanov, M., Sigsgaard, C., Dlugokencky, E. J., Houweling, S., Strom, L., Tamstorf, M. P., and Christensen, T. R.: Large tundra methane burst during onset of freezing, Nature, 456, 628-U658, doi:10.1038/Nature07464, 2008.

Merritt, W. S., Letcher, R. A., and Jakeman, A. J.: A review of erosion and sediment transport models, Environ. Model. Softw., 18, 761-799, doi:10.1016/S1364-8152(03)00078-1, 2003.

Moldrup, P., Olesen, T., Komatsu, T., Yoshikawa, S., Schjønning, P., and Rolston, D. E.: Modeling Diffusion and Reaction in Soils: X. A Unifying Model for Solute and Gas Diffusivity in Unsaturated Soil, Soil Sci., 168, 321-337, doi:10.1097/01.ss.0000070907.55992.3c, 2003.

Nearing, M. A., Lane, L. J., and Lopes, V. L.: Modeling soil erosion, in: Soil Erosion Research Methods, edited by: Lal, R., Soil and Water Conservation Society, Ankeny, 127-156, 1994.

Oleson, K. W., Lawrence, D. M., Bonan, G. B., Flanner, M. G., Kluzek, E., Lawrence, P. J., Levis, S., Swenson, S. C., Thornton, P. E., Dai, A., Decker, M., Dickinson, R., Feddema, J., Heald, C. L., Hoffman, F., Lamarque, J.-F., Mahowald, N., Niu, G.-Y., Qian, T., Randerson, J., Running, S., Sakaguchi, K., Slater, A., Stöckli, R., Wang, A., Yang, Z.-L., Zeng, X., and Zeng, X.: Technical description of version 4.0 of the Community Land Model, Natl. Cent. for Atmos. Res., Boulder, CO, 2010.

Parton, W. J., Stewart, J. W. B., and Cole, C. V.: Dynamics of C, $\mathrm{N}, \mathrm{P}$ and $\mathrm{S}$ in Grassland Soils - a Model, Biogeochemistry, 5, 109-131, 1988.

Plhak, F.: Nitrogen supply through transpiration mass flow can limit nitrogen nutrition of plants, Plant Soil Environ., 49, 473-479, 2003.

Potter, C., Klooster, S., Myneni, R., Genovese, V., Tan, P. N., and Kumar, V.: Continental-scale comparisons of terres- trial carbon sinks estimated from satellite data and ecosystem modeling 1982-1998, Global Planet. Chang., 39, 201-213, doi:10.1016/J.Gloplacha.2003.07.001, 2003.

Press, W. H., Flannery, B. P., Teukolsky, S. A., and Vetterling, W. T.: Numerical Recipes, Cambridge University Press, New York, 1986.

Qian, T. T., Dai, A., Trenberth, K. E., and Oleson, K. W.: Simulation of global land surface conditions from 1948 to 2004, Part I: Forcing data and evaluations, J. Hydrometeorol., 7, 953-975, 2006.

Randerson, J. T., Thompson, M. V., Conway, T. J., Fung, I. Y., and Field, C. B.: The contribution of terrestrial sources and sinks to trends in the seasonal cycle of atmospheric carbon dioxide, Global Biogeochem. Cy., 11, 535-560, 1997.

Raymond, W. H. and Kuo, H. L.: A Radiation Boundary-Condition for Multi-Dimensional Flows, Q. J. Roy. Meteorol. Soc., 110, 535-551, 1984.

Riley, W. J.: A modeling study of the impact of the delta $\delta^{18} \mathrm{O}$ value of near-surface soil water on the delta $\delta^{18} \mathrm{O}$ value of the soilsurface $\mathrm{CO}_{2}$ flux, Geochim. Cosmochim. Acta, 69, 1939-1946, doi:10.1016/J.Gca.2004.10.021, 2005.

Riley, W. J., Subin, Z. M., Lawrence, D. M., Swenson, S. C., Torn, M. S., Meng, L., Mahowald, N. M., and Hess, P.: Barriers to predicting changes in global terrestrial methane fluxes: analyses using CLM4Me, a methane biogeochemistry model integrated in CESM, Biogeosciences, 8, 1925-1953, doi:10.5194/bg-8-19252011, 2011.

Sakaguchi, K. and Zeng, X. B.: Effects of soil wetness, plant litter, and under-canopy atmospheric stability on ground evaporation in the Community Land Model (CLM3.5), J. Geophys. Res.Atmos., 114, D01107, doi:10.1029/2008jd010834, 2009.

Sander, R.: Compilation of Henry's law constants for inorganic and organic species of potential importance in environmental chemistry (version 3), available at: www.henrys-law.org/henry.pdf (last access: 25 January 2013), 1999.

Schmidt, M. W., Torn, M. S., Abiven, S., Dittmar, T., Guggenberger, G., Janssens, I. A., Kleber, M., Kogel-Knabner, I., Lehmann, J., Manning, D. A., Nannipieri, P., Rasse, D. P., Weiner, S., and Trumbore, S. E.: Persistence of soil organic matter as an ecosystem property, Nature, 478, 49-56, doi:10.1038/nature10386, 2011.

Simunek, J. and Suarez, D. L.: Modeling of Carbon-Dioxide Transport and Production in Soil, 1. Model Development, Water Resour. Res., 29, 487-497, 1993.

Song, C., Xu, X., Sun, X., Tian, H., Miao, Y., Wang, X., and Guo, Y.: Large methane emissions upson spring thaw from natural wetlands in the northern permafrost region, Environ. Res. Lett., 7, 034009, doi:10.1088/1748-9326/7/3/034009, 2012.

Strang, G.: On Construction and Comparison of Difference Schemes, Siam. J. Numer. Anal., 5, 506-517, 1968.

Swenson, S. C., Lawrence, D. M., and Lee, H.: Improved simulation of the terrestrial hydrological cycle in permafrost regions by the Community Land Model, J. Adv. Model. Earth Syst., 4, M08002, doi10.1029/2012ms000165, 2012.

Tang, J. Y. and Riley, W. J.: A new top boundary condition for modeling surface diffusive exchange of a generic volatile tracer: theoretical analysis and application to soil evaporation, Hydrol. Earth Syst. Sci. Discuss., 9, 11941-11998, doi:10.5194/hessd-911941-2012, 2012. 
Tang, J. Y., Zhuang, Q., Shannon, R. D., and White, J. R.: Quantifying wetland methane emissions with process-based models of different complexities, Biogeosciences, 7, 3817-3837, doi:10.5194/bg-7-3817-2010, 2010.

Teskey, R. O., Saveyn, A., Steppe, K., and McGuire, M. A.: Origin, fate and significance of $\mathrm{CO}_{2}$ in tree stems, New Phytologist, 177, 17-32, doi:10.1111/J.1469-8137.2007.02286.X, 2008.

Thornton, P. E., Law, B. E., Gholz, H. L., Clark, K. L., Falge, E., Ellsworth, D. S., Golstein, A. H., Monson, R. K., Hollinger, D., Falk, M., Chen, J., and Sparks, J. P.: Modeling and measuring the effects of disturbance history and climate on carbon and water budgets in evergreen needleleaf forests, Agr. Forest Meteorol., 113, 185-222, 2002.

Thornton, P. E., Lamarque, J.-F., Rosenbloom, N. A., and Mahowald, N. M.: Influence of carbon-nitrogen cycle coupling on land model response to $\mathrm{CO}_{2}$ fertilization and climate variability, Global Biogeochem. Cy., 21, GB4018, doi:10.1029/2006gb002868, 2007.

Tokida, T., Mizoguchi, M., Miyazaki, T., Kagemoto, A., Nagata, O., and Hatano, R.: Episodic release of methane bubbles from peatland during spring thaw, Chemosphere, 70, 165-171, doi:10.1016/J.Chemosphere.2007.06.042, 2007.

Torn, M. S. and Harte, J.: Missing feedbacks, asymmetric uncertainties, and the underestimation of future warming, Geophys. Res. Lett., 33, L10703, doi:10.1029/2005gl025540, 2006.

Tremback, C. J., Powell, J., Cotton, W. R., and Pielke, R. A.: The Forward-in-Time Upstream Advection Scheme - Extension to Higher Orders, Mon. Weather Rev., 115, 540-555, 1987.
Walter, B. P. and Heimann, M.: A process-based, climate-sensitive model to derive methane emissions from natural wetlands: Application to five wetland sites, sensitivity to model parameters, and climate, Global Biogeochem. Cy., 14, 745-765, 2000.

Wania, R., Ross, I., and Prentice, I. C.: Implementation and evaluation of a new methane model within a dynamic global vegetation model: LPJ-WHyMe v1.3.1, Geosci. Model Dev., 3, 565-584, doi:10.5194/gmd-3-565-2010, 2010.

Wu, Y. H., Walker, J., Schwede, D., Peters-Lidard, C., Dennis, R., and Robarge, W.: A new model of bi-directional ammonia exchange between the atmosphere and biosphere: Ammonia stomatal compensation point, Agr. Forest Meteorol., 149, 263-280, doi:10.1016/J.Agrformet.2008.08.012, 2009.

Yoo, K., Ji, J. L., Aufdenkampe, A., and Klaminder, J.: Rates of soil mixing and associated carbon fluxes in a forest versus tilled agricultural field: Implications for modeling the soil carbon cycle, J. Geophys. Res.-Biogeo., 116, G01014, doi:10.1029/2010jg001304, 2011.

Zhuang, Q., McGuire, A. D., Melillo, J. M., Clein, J. S., Dargaville, R. J., Kicklighter, D. W., Myneni, R. B., Dong, J., Romanovsky, V. E., Harden, J., and Hobbie, J. E.: Carbon cycling in extratropical terrestrial ecosystems of the Northern Hemisphere during the 20th century: a modeling analysis of the influences of soil thermal dynamics, Tellus Ser. B, 55, 751-776, 2003. 